\title{
High-Quality Learning Environments for Engineering Design: Using Tablet PCs and Guidelines from Research on How People Learn
}

\author{
Enrique Palou ${ }^{a}, b,{ }^{a}$, Lourdes Gazca ${ }^{a}$, Juan Antonio Díaz García ${ }^{a, c}$, José Andrés \\ Rojas Lobato ${ }^{a, c}$, Luis Gerardo Guerrero Ojeda ${ }^{a}$, José Francisco Tamborero \\ Arnal $^{\mathrm{a}, \mathrm{c}}$, María Teresa Jiménez Munguía ${ }^{\mathrm{a}, \mathrm{b}}$, Aurelio López-Malo ${ }^{\mathrm{a}, \mathrm{b}}$, and Juan \\ MANUEL GARIBAY ${ }^{\mathrm{a}}$

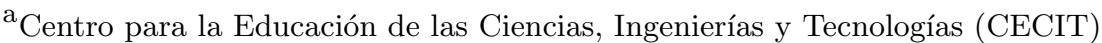
${ }^{\mathrm{b}}$ Departamento de Ingeniería Química, Alimentos y Ambiental
${ }^{c}$ Departamento de Ingeniería Industrial y Mecánica
Universidad de las Américas Puebla, Cholula, Puebla 72810, Mexico \\ *enrique.palou@udlap.mx
}

Received: 13 July 2011; Published online: 18 April 2012

\begin{abstract}
A team of several faculty members and graduate students at Universidad de las Américas Puebla is improving engineering design teaching and learning by creating richer learning environments that promote an interactive classroom while integrating formative assessment into classroom practices by means of Tablet PCs and associated technologies. Learning environments that are knowledge-, learner-, community-, and assessment-centered as highlighted by the How People Learn framework, have been developed. To date, the redesign of the undergraduate course entitled Introduction to Engineering Design has significantly $(p<0.05)$ increased student participation; formative assessment and feedback are more common and rapid; and instructors are utilizing the information gained through real-time formative assessments to tailor instruction to meet student needs. Particularly important have been opportunities to make student thinking visible and to give them chances to revise, as well as opportunities for "what if" thinking.
\end{abstract}

Keywords: learning environments; engineering design; tablet PC; formative assessment; How People Learn

\section{Introduction}

Universidad de las Américas Puebla (UDLAP) is a Mexican private institution of higher learning committed to first class teaching, public service, research and learning in a wide range of academic disciplines including business administration, the physical and social sciences, engineering, humanities, and the arts. The studied course, Introduction to Engineering Design (EI-100), is a first semester 3 credit course required for almost ev- ery UDLAP engineering program since the spring of 2001. Course content and classroom activities are divided into three, two hour sessions ("Modeling", "Concepts", and "Laboratory") per week. Students have six different EI-100 instructors (one teacher and a teaching assistant for each session). The goal of EI-100 is to introduce students to the Engineering Method, which is accomplished by focusing on six course objectives: self-regulation, communication, working co-operatively and collaboratively, problem solv- 
2 |Palou et al.

ing, modeling, and quality (Palou \& Tamborero, 2009). The "Modeling" session initiates students in the process of engineering modeling, using several software programs, including spreadsheets. "Concepts" introduce students to the engineering design process, problem-solving techniques, working in teams, engineering as a profession, and planning for success that students then apply in "Laboratory" on two actual design projects. The "Concepts" session uses quizzes given in nearly every session to ascertain whether students have understood the material in their preclass reading assignments. In addition, we encourage students to write brief reflective journal entries to further solidify and reinforce their own understanding, as well as to demonstrate that improved understanding and therefore improve their quiz grade. UDLAP's Chemical, Civil, Computer, Electrical, Environmental, Food, Industrial, Mechanical, and Mechatronic engineering students have in EI-100 a great opportunity for a multidisciplinary collaborative experience. EI-100 is a team-taught course that uses active, collaborative and cooperative learning, which has been a major player in UDLAP's efforts to reform engineering education since 2001 (Palou $\&$ Tamborero, 2009). The major goal of this project was to improve engineering design teaching and learning by creating richer learning environments that promote an interactive classroom while integrating formative assessment into EI100 classroom practices. By re-designing the EI100 course we could improve student understanding of the engineering method and student ability to solve practical engineering problems, and complete real-world engineering projects while increasing active student participation, peer-team interactions and feedback processes.

\section{Theoretical Background}

EI-100 could be improved by taking into account technological advances and recent research on human learning and cognitive processes that underlie expert performances.

\subsection{Using information about How People Learn}

During the past 30 years, research on human learning has exploded. Although we have a long way to go to fully uncover the mysteries of learning, we know a considerable amount about the cognitive processes that underlie expert performances and about strategies for helping people increase their expertise in a variety of areas (Bransford, Vye, \& Bateman, 2002). Several committees organized by the US National Academy of Sciences have summarized much of this research in reports published by the National Academy Press. A key publication that informs our current discussion is How People Learn: Brain, Mind, Experience and School (Bransford, Brown, \& Cocking, 2000). Knowing What Students Know (Pellegrino, Chudowsky, \& Glaser, 2001), which builds on How People Learn, is also relevant to this discussion. Its focus is primarily on assessment. An organizing structure used in the How People Learn volumes (hereafter HPL) is the HPL framework. It highlights a set of four overlapping lenses that can be used to analyze any learning situation. In particular, it suggests that we ask about the degree to which learning environments are:

Knowledge-centered In the sense of being based on a careful analysis of what we want people to know and be able to do when they finish with our materials or course and providing them with the foundational knowledge, skills, and attitudes needed for successful transfer.

Learner-centered In the sense of connecting to the strengths, interests, and preconceptions of learners and helping them learn about themselves as learners.

Community-centered In the sense of providing an environment, both within and outside the classroom, where students feel safe to ask questions, learn to use technology to access resources and work collaboratively, and are helped to develop lifelong learning skills.

Assessment-centered In the sense of providing multiple opportunities to make students

\begin{tabular}{l|l|l|l} 
IJFS & April 2012 & Volume 1 & pages 1-16
\end{tabular} 
thinking visible so they can receive feedback and be given chances to revise.

The HPL framework provides a convenient way to organize a great deal of information about the nature of competent (expert) performance and about ways to help people develop their own competence (Bransford et al., 2002). The framework highlights a set of four overlapping lenses that are useful for analyzing the quality of various learning environments. Balance is particularly important. For example, learning environments can be knowledge-centered but not learner-centered, and vice versa. In addition, many environments lack frequent opportunities for formative assessment and revision, and many fail to promote a sense of community where learning (which includes admissions of "not knowing") is welcomed (Bransford et al., 2000; Bransford et al., 2002; Pellegrino et al., 2001).

\subsection{Tablet PCs}

In an increasingly collaborative, mobile and globally inter-connected environment, UDLAP envisions ubiquitous computing as a natural, empowering component of every teaching, learning, and research activity. Through its Science, Engineering and Technology Education (CECIT) research center, UDLAP is exploring ways to accelerate the transformation of information technologies into knowledge technologies that effectively support students and faculty in their academic projects. Tablet PCs combine a standard notebook computer with a digitizing screen and a pen-like stylus device to produce a computer that allows ease of input of natural writing and drawing. Tablet PC touch screen or digitizing tablet technology allows the user to operate the computer with a stylus or digital pen or a fingertip instead of a keyboard or mouse. Early adopters in higher education have developed Tablet PC teaching platforms that incorporate active learning techniques and support in-class teacher-student and student-student collaborations. Novel software is available to grade assignments, conduct on-line office hours, tutor courses, and illustrate several topics, among many other applications. Tablet PC technologies offer flexibility and a range of expression that can achieve a wide range of educational goals and foster a more participatory classroom environment. Pedagogically, applications for the Tablet PC include lecture/presentation enhancement, problem-solving demonstrations, active learning support, guided brainstorming, reading, commenting, marking-up (providing feedback), and grading of student work. A review (Wise, Toto, \& Yon Lim, 2006) of the current literature supports the following advantages in using a Tablet PC: First, digital ink enables instructors to write "on the fly" during class as one would write on a chalkboard or on a transparency. This is especially meaningful for engineering courses where examples and explanations are often mathematically and graphically intensive. Second, the freedom of marking-up significantly changes the way students and teachers interact. It facilitates bidirectional sharing of information, moving students beyond merely observing presentations to interacting with the material, the teacher, and each other. In addition, the use of Tablet PCs supports more efficient management of information. Dynamic working notes can be saved in a searchable format, while lecture notes with vivid annotations become available for students online viewing.

\subsection{Strategy to redesign EI-100}

A major issue is how to help students develop the kinds of connected knowledge, skills, and attitudes that prepare them for effective lifelong learning. This involves the need to seriously rethink not only how to help students learn about particular isolated topics but to rethink the organization of entire courses and curricula. People who want to improve educational quality often begin with a focus on teaching methods. Questions about teaching strategies are important, but they need to be asked in the context of whom we are teaching and what we want our students to accomplish (Bransford et al., 2000). The reason is that particular types of teaching and learning strategies can be strong or weak depending on our goals for learning and the knowledge and skills that students bring to the learning task (Schwartz \& Bransford, 1998; Jenkins, 1979). A 
4 | Palou et al.

model developed by Jenkins (1979) highlights important constellations of factors that must be simultaneously considered when attempting to think about issues of teaching and learning. The model illustrates that the appropriateness of using particular types of teaching strategies depends on:

1. the nature of the materials to be learned;

2. the nature of the skills, knowledge, and attitudes that learners bring to the situation; and

3. the goals of the learning situation and the assessments used to measure learning relative to these goals.

A particular teaching strategy may flourish or perish depending on the overall characteristics of the ecosystem in which it is placed (Bransford et al., 2000). The Jenkins model fits well with a proposal by Wiggins and McTighe (1997). They suggest a "working backwards" strategy for creating high-quality learning experiences. In particular, they recommend that educators:

1. begin with a careful analysis of learning goals;

2. explore how to assess students progress in achieving these goals; and

3. use the results of steps 1 and 2 to choose and continually evaluate teaching methods.

Assumptions about steps 1 and 2 are also continually evaluated. When using a "working backwards" strategy for EI-100, our choice of teaching strategies derives from a careful analysis of learning goals, rather than vice versa.

\section{Implementation}

The ability to design engineering undergraduate courses and corresponding high-quality learning environments requires that we move beyond procedural strategies and models. We also need to understand the kinds of skills, attitudes, and knowledge structures that support competent performance. Thus, for the redesign of the
EI-100 course, we "worked backwards" taking into account Jenkins model as well as the HPL framework. Especially important was knowledge of key concepts and models that provide the kinds of connected, organized knowledge structures and accompanying skills and attitudes that can set the stage for future learning (Bransford \& Schwartz, 1999).

\subsection{Comparison with the previous course}

Effective design requires collaboration among people with specific kinds of expertise (content knowledge, learning, assessment, technology). CECIT expertise was used to enhance Tablet PC technologies to effectively support students and faculty in EI-100 academic projects. CECIT also contributed in the design of rubrics and assessment procedures (including classroom activities), as well as evaluation of learning outcomes for the redesigned EI-100 course using Tablet PC technologies and HPL framework to compare the results of the previous course (we have comprehensive data from seven years of implementation) and the redesigned one to be sure of the impact of this proposal on teaching, classroom activities and student learning (Bransford et al., 2000; Pellegrino et al., 2001; Shavelson \& Towne, 2002). Main evaluation questions of this project are:

1. Are students gaining a deeper conceptual understanding of the engineering method than they did before the course was redesigned?

2. Has active student participation in class increased as compared with previous, non-Tablet PC technologies and HPL framework-enhanced versions of the same course?

3. Are formative assessment and feedback more common and rapid in the redesigned course than in the previous course offerings?

4. Do the instructors utilize the information gained through real-time formative assessment to tailor instruction to meet student needs? 
5. Are peer-team formative assessments better than in the previous course offerings?

6. Does the redesigned course improve feedback processes so that "Laboratory" work resubmission decreases?

\subsection{Redesign of EI-100}

Our redesign involved a transformation of EI-100 from a lecture-based format to a challenge-based format. We use the term "challenge-based" as a general term for a variety of approaches to instruction that many have studied, which include case-based instruction, problem-based learning, learning by design, inquiry learning, anchored instruction, and so forth. There are important differences among these approaches, but important commonalities as well (Bransford et al., 2000; Felder, Woods, Stice, \& Rugarcia, 2000). We used the HPL framework as a set of lenses for guiding the redesign of the lessons, development of our challenges but also the overall instruction that surrounded the challenges. Particularly important were opportunities to make students thinking visible and give them chances to revise (Bransford et al., 2000). We also noted the importance of providing opportunities for "what if" thinking, given variations on the challenge and for new problems that also involved the lessons concepts. Attempts to help people reflect on their own processes as learners (to be metacognitive) were also emphasized.

\subsection{VaNTH Observation System}

The VaNTH Observation System (VOS) was used to systematically assess HPL framework implementation in EI-100 classrooms (Harris \& Cox, 2003; Gazca, Palou, López-Malo, \& Garibay, 2009a) . VOS is an assessment tool developed to capture qualitative and quantitative classroom observation data from teaching and learning experiences in the bioengineering classroom. VOS is a four-part system that incorporates the elements of HPL framework and uses four recurring methods of collecting classroom data: recording student-teacher interactions (CIO), recording student academic engage- ment (SEO), recording narrative notes of classroom events $(\mathrm{NN})$, and rating specific indicators of effective teaching (GR). Observers measured differences in classroom experiences resulting from the innovations and redesigned learning environments. Over the course of the past year, three observers trained in VOS sat in EI100 classrooms and observed 9 instructors, both junior and senior level, in over 60 class sessions from the three different EI-100 sessions. Classes ranged in size from 30 to 70-plus; some were designated as control (prior to redesign) classes, and others as experimental (redesigned) classes. Observers conducted a minimum of six observations per class. For the experimental and control classes, observation dates were randomly selected throughout the semester. This past semester, observers achieved a 70 percent inter-rater reliability in using the VOS (Gazca et al., 2009a). To make the first semester student design experience even more visible, we conducted an ethnographic study (Gazca, Palou, López-Malo, \& Garibay, 2009b) in addition to VOS ethnographic components (Cox \& Harris, 2006; Harris, 2003). Conducting an ethnographic study is an exercise in making visible experiences that get hidden (LeCompte \& Schensul, 1999). In this case, our task was to make visible patterns in first semester student experiences with the dominant model of engineering problem-solving. Conducting intensive ethnographic research for two semesters in EI-100 classrooms, our team produced 500 pages of transcribed and coded data drawn from biweekly interviews with focus groups, individual interviews, and assorted assignments, journals, projects, quizzes, presentations and lectures.

\subsection{Software}

Vast amounts of educational and psychological research support the efficacy of both active learning and frequent real-time formative assessment in improving learning (Bransford et al., 2000; Bransford et al., 2002; Felder et al., 2000; Johnson, Johnson, \& Smith, 1998). In EI-100 we utilized InkSurvey, a web-based tool developed specifically to allow an instructor to pose open-ended questions to students during class and receive real-time student responses (Kowal- 
ski, Kowalski, \& Hoover, 2007). EI-100 students utilized Tablet PCs to respond to the challenging questions (posed by instructors) with their own words/sentences/paragraphs entered manually via the keyboard, or with digital ink that allows handwriting, as well as input of student sketches, equations, graphs, derivations, etc. Students confidence level in their responses can be included since InkSurvey has that capability. EI-100 instructors received an instantaneous compilation of web-based student responses. The instructor then displayed selected team responses to the rest of the class on the classroom presentation screen to make students thinking visible and give them chances to revise, as well as to provide opportunities for "what if" thinking, given variations on the challenge. A variety of Tablet PC compatible tools are being used to facilitate communication within the classroom, such as Classroom Presenter and DyKnow. Using the work of Angelo and Cross (1993), EI-100 faculty identified classroom assessment techniques (CATs) appropriate to each session of the course and then adapted them into the Tablet PC / Classroom Presenter environment. Faculty also made use of CATs that are already features within Classroom Presenter, like the polling features (Anderson, McDowell, \& Simon, 2005). Each EI-100 instructor uses CATs to gauge student learning in real time and makes real-time pedagogical adjustments as needed. One of the more powerful features of Classroom Presenter is the ability to perform student submissions. Using this feature, EI-100 instructors posed a problem to the student teams and requested that they work on a solution to the problem and then submit it to the instructor Tablet PC. The instructor then displayed selected team submissions to the rest of the class on the classroom presentation screen and developed a discussion around various opinions or competing solutions to the problem. Having used this capability in the EI-100 course, we have had much success in energizing the class and increasing student participation in classroom activities since upon displaying the submission, the rest of the teams are asked to verify its correctness, seek an optimal solution, or propose alternative solutions. Students were very eager to participate in these types of exercises as reported elsewhere (Anderson et al., 2005; Kowal- ski et al., 2007; Tront, Eligeti, \& Prey, 2006; Wise et al., 2006). Tools for solving engineering problems have become computer-based over recent years. In order to effectively demonstrate the use of computer-based tools in a classroom environment, teachers typically present the tool by projecting the computer screen display and verbally describing the operation. Annotating presentation information using a real-time stylus is a powerful feature by which one can illustrate and elucidate the lecture topic by inking on pre-drawn text, pictures or drawings. However, the ability to annotate on any application further enhances the capability of the lecturing by not restricting the instructors to only static displays of prepared images (Tront et al., 2006). For example, instructors teaching the "Modeling" session could more effectively explain their subject if they could demonstrate an execution process in real-time to the class by showing output of a simulator that is using a model created by the students. In EI-100 we utilized WriteOn, a Tablet PC tool that was developed to allow the user to effectively draw on top of any application shown on the Tablet PC screen. Conceptually set up as a virtual transparency, WriteOn allows a presenter to annotate on an operational window as the target application dynamically runs (Tront et al., 2006). Therefore, WriteOn adds the ability to annotate on top of the screen displaying the changes within the simulator as the "Modeling" session simulation takes place. Snapshots of the screen, including the electronic ink as well as the application output, can be captured and stored as class notes for later distribution through EI-100 website. WriteOn and Classroom Presenter allow the presenter to generate a movie of the screen activity including voice-over of the classroom discussion. Finally, WriteOn and Classroom Presenter can also broadcast the presenters screen content to the entire class using wireless networking. In this mode the student clients can both receive the application output and the instructors annotations as well as add their own annotations to the presentation. Students can then store a local copy of the fully annotated presentation on their machine for later review. An important learning goal of EI-100 is to enhance students written and oral communication skills therefore multiple opportunities were 
given to the students to practice, receive feedback and enhance their written work-products and oral presentations. An additional skill we want students to develop over the semester is the ability to critically evaluate their own and others work. In order to do this, students self-assessed most of their work while in "Laboratory" almost every week they peer-assessed other teams work. This is a skill we think is very important to develop in future engineers so we take the peer assessment process seriously. For this to be an effective process, students must learn how to give and to take constructive feedback. We utilized 21 Tablet PCs to redesign EI-100. The instructor utilized one Tablet and a team of 4 students utilized each one of the other twenty Tablet PCs. In particular, we were interested in using Tablet $\mathrm{PC}$ technologies to encourage active learning (interactive engagement) and probe student understanding through frequent formative assessment. The course was taught in a large classroom with 20 tables with four students each. The classroom had six boards, two LCD-projectors and two screens. The instructor Tablet PC was wireless connected to the projectors, so instructors were able to move within the classroom with his/her computer. The classroom was equipped with a sound system with a tie clip microphone for the instructor and two wireless microphones for the students.

\section{Results and Discussion}

\subsection{Classroom practice}

The goals of this project fall into student learning (improve student understanding of the Engineering Method and ability to solve practical problems and complete real-world engineering projects) and classroom environment (increase active student participation and peer interactions as teams, as well as improve feedback processes). The VaNTH Observation System was used to systematically assess HPL framework implementation in the classroom while existing assessment measures were also used to compare the results of the redesigned (2008) EI-100 course with previous EI-100 courses since we had comprehensive data from six years (2001-2007) of implementation prior to the year (2008) the redesigned course was offered. Students in every studied section (2001-2008) were comparable in terms of gender, grade point average (GPA), and engineering major. Primary sources of evidence for this project come directly from student work products (including projects, models, assignments, quizzes, and journals). Students in the re-designed course:

1. Asked probing questions in the field that demonstrated an initial understanding of the Engineering Design Method: "a systematic, intelligent process in which designers generate, evaluate, and specify concepts for devices, systems, or processes whose form and function achieve clients' objectives or users' needs while satisfying a specified set of constraints" (Dym, Agogino, Eris, Frey, $\&$ Leifer, 2005). The probing questions were mainly asked (Gazca et al., 2009b) while working in projects (in "Laboratory") and models (in "Modeling"), and in many student journals (in "Concepts"). We hypothesize that frequent formative assessments using Tablet PC technologies have helped in this matter. Thus a qualitative research project is underway to further investigate this matter.

2. Produced high quality projects that were thorough, insightful, and clear. There are two major "Laboratory" projects (Palou \& Tamborero, 2009): one "faculty-guided" and related to reverse engineering, the other with minimal guide from faculty, is a community service project that helps us to assess student knowledge transfer using the "preparation for future learning" paradigm (Bransford \& Schwartz, 1999; Bransford et al., 2000). We hypothesize that frequent formative assessments (including peer-team assessments) using Tablet PC technologies have helped in this matter. Therefore, further qualitative research is underway.

3. Reflected conceptual understanding in their six team models, and made fewer errors (assessed by instructors using an ad-hoc rubric) than in the previous 14 semesters (20012007 ) in their models with a mean drop in 
$8 \mid$ Palou et al.

model errors of around $6 \%$. As a result, their models were more accurate and showed logical thought progressions in finding solutions to problems.

4. Performed better (in 2008) than in the previous 14 semesters on several course assessments with mean increases (in aggregated student scores) that can be seen in 4.1. The course assessments include "Laboratory" two team projects, "Modeling" six team models, as well as "Concepts" three individual assignments, seven individual quizzes, and seven individual journals.

5. Performed better in 2008 peer assessments (when compared to instructor assessments using the same corresponding rubric) than in the previous 14 semesters. In this case a modest increase (lower than 5\%) was observed. However, this had an important impact decreasing resubmission of team work-products in "Laboratory". Also, using Tablet PC technologies instead of paperbased assessments shortened feedback cycles between student teams.

In keeping with this projects emphasis on changes to classroom practice, the following were also observed in the re-designed course:

1. During 2008, a greater percentage (mean increase around $13 \%$ ) of students actively participated in class sessions than in the previous semester (Fall 2007).

2. Instructors solicited information about student understanding more frequently during 2008 than in the previous semester (Fall 2007 ) with a mean increase around $20 \%$. Moreover, they provided more feedback than in the previous semester to students and in a timely manner. Further, instructors refined instruction based on feedback from students. We hypothesize that these frequent formative assessments and corresponding feedback and instructional changes have helped in several learning aspects (as mentioned above). Thus, further qualitative research is underway.
Table 1: Mean increases (in aggregated student scores) between results from Fall 2008 and previous 14 semesters for selected assessments of the course Introduction to Engineering Design

\begin{tabular}{|c|c|}
\hline $\begin{array}{c}\text { Course } \\
\text { Assessment }\end{array}$ & $\begin{array}{c}\text { Mean } \\
\text { Increase }(\%)\end{array}$ \\
\hline \multicolumn{2}{|l|}{ "Laboratory" } \\
\hline 1st team project & 6.2 \\
\hline 2nd team project & 9.3 \\
\hline \multicolumn{2}{|l|}{ "Modeling" } \\
\hline Model 1 & 3.1 \\
\hline Model 2 & 2.9 \\
\hline Model 3 & 5.3 \\
\hline Model 4 & 6.0 \\
\hline Model 5 & 6.6 \\
\hline Model 6 & 7.5 \\
\hline \multicolumn{2}{|l|}{ "Concepts" } \\
\hline Assignment 1 & 0.8 \\
\hline Assignment 2 & 5.1 \\
\hline Assignment 3 & 10.0 \\
\hline Quiz 1 & 2.0 \\
\hline Quiz 2 & 3.3 \\
\hline Quiz 3 & 2.8 \\
\hline Quiz 4 & 4.2 \\
\hline Quiz 5 & 6.0 \\
\hline Quiz 6 & 8.1 \\
\hline Quiz 7 & 8.2 \\
\hline Journal 1 & 2.2 \\
\hline Journal 2 & 3.3 \\
\hline Journal 3 & 2.6 \\
\hline Journal 4 & 4.2 \\
\hline Journal 5 & 6.6 \\
\hline Journal 6 & 8.0 \\
\hline Journal 7 & 8.7 \\
\hline
\end{tabular}

Because of the anonymity afforded by Tablet PC technologies, students felt comfortable sharing their ideas with classmates, which enabled instructors to assess student understanding frequently during the processes of instruction, problem solving, and peer evaluations to quickly identify the most common difficulties, provide immediate feedback, redirect classroom activities, and/or refine instruction based on feedback received. Particularly important were opportunities to make students thinking visible, give them chances to revise, and for "what if" thinking, as well as to help students reflect on their own processes as learners (to be metacognitive). 


\subsection{HPL dimensions}

The Introduction to Engineering Design course has undergone many changes since its inception in Spring 2001, the most important of which have sought to orient the course towards the How People Learn framework in spring 2008. The VaNTH Observation System enabled us to identify two very important aspects of the redesigned EI-100 in its two Fall 2008 sections (1 and 2) and three sessions ("Modeling", "Concepts" and "Laboratory"). On one hand, this led us to determine that it is in fact a course designed according to the HPL framework, and that every one of the sessions, following the framework under which they were redesigned, employs learning environments that are knowledge-, learner-, assessment, and community-centered (Gazca et al., 2009a, 2009b). The CIO instrument of VOS allowed us to determine what the HPL-centeredness level was in each of the three sessions ("Modeling", "Concepts" and "Laboratory") of the course by answering how the classroom interaction took place. 1 presents the differences observed among the different sessions of the EI-100 course in terms of the level of HPL-centeredness exhibited in the classroom. Every one of the sessions carried out knowledge-, student-, assessment-, and community-centered activities. The percentages relating to organization-centered activities were nearly insignificant (less than 2\%) and therefore are not present.

In a pattern common to all sessions, the highest percentage was found in knowledge-centered activities, with a percentage of approximately $30 \%$ in the three groups observed. "Modeling" and "Laboratory" sessions displayed the secondhighest percentages in community-centered activities. These results are logical if one considers that in these two sessions most problems and projects are solved in teams and most of them are related to the real world. On the other hand, the "Concepts" sessions, which comprise the theoretical portion of the EI-100 course, had their second-highest percentage in learner-centered activities, followed by assessment-centered activities. It is important to point out that even though there are differences between the percentages of HPL-centered activities, EI-100 is aligned with the HPL framework and therefore course redesign was successful in that regard. Similar successful results have been reported (Birol, Liu, Smith, \& Hirsch, 2006; Cordray, Harris, \& Harris, 2007; Cox \& Cordray, 2008). However, there are opportunities for improvement; in "Concepts" it would be desirable to increase the percentage of community-centered activities, while "Laboratory" needs to work on increasing the amount of learner-centered activities. We utilized VOS to systematically assess HPL framework implementation in EI-100 classrooms and comprehensive results from VOS are reported elsewhere (Gazca et al., 2009a). Based on the use of the first three VOS instruments (CIO, NN and GR), it may be concluded that the redesigned course embraces several characteristics that should be present in an HPL-centered classroom such as students explaining how to solve a problem, cooperative learning taking place in the classroom, the professor guiding higher-order discussions, and the professor leading an HPL-based question and answer session. Further, several characteristics that should be promoted by a professor conducting an HPL-oriented class were also observed, for instance offering HPL challenges; connecting with prior learning; formatively assessing at the beginning, during, and at the end of class; using appropriate visual aids; and asking hypothetical questions. Likewise, use of the three instruments allowed us to discern important differences among professors. What stood out was that the sessions with the highest percentages of HPLoriented activities were those taught by instructors who had more experience with the course and the HPL framework. This demonstrates the need that exists, on the one hand, to train professors on the HPL framework so that they can develop an in-depth knowledge of it and then apply it in the classroom, and on the other hand, the importance of the professors experience in using HPL framework. Further, we conducted an ethnographic study, which included participatory observation, informal interviews (students, teachers, teaching assistants, alumni, and employers), course exit surveys, and analysis of secondary materials to make visible experiences that get hidden when using VOS. Our goal was to gain a clear understanding of what was happening in EI-100, seeking to get to know the course culture from the points of view of many of its 


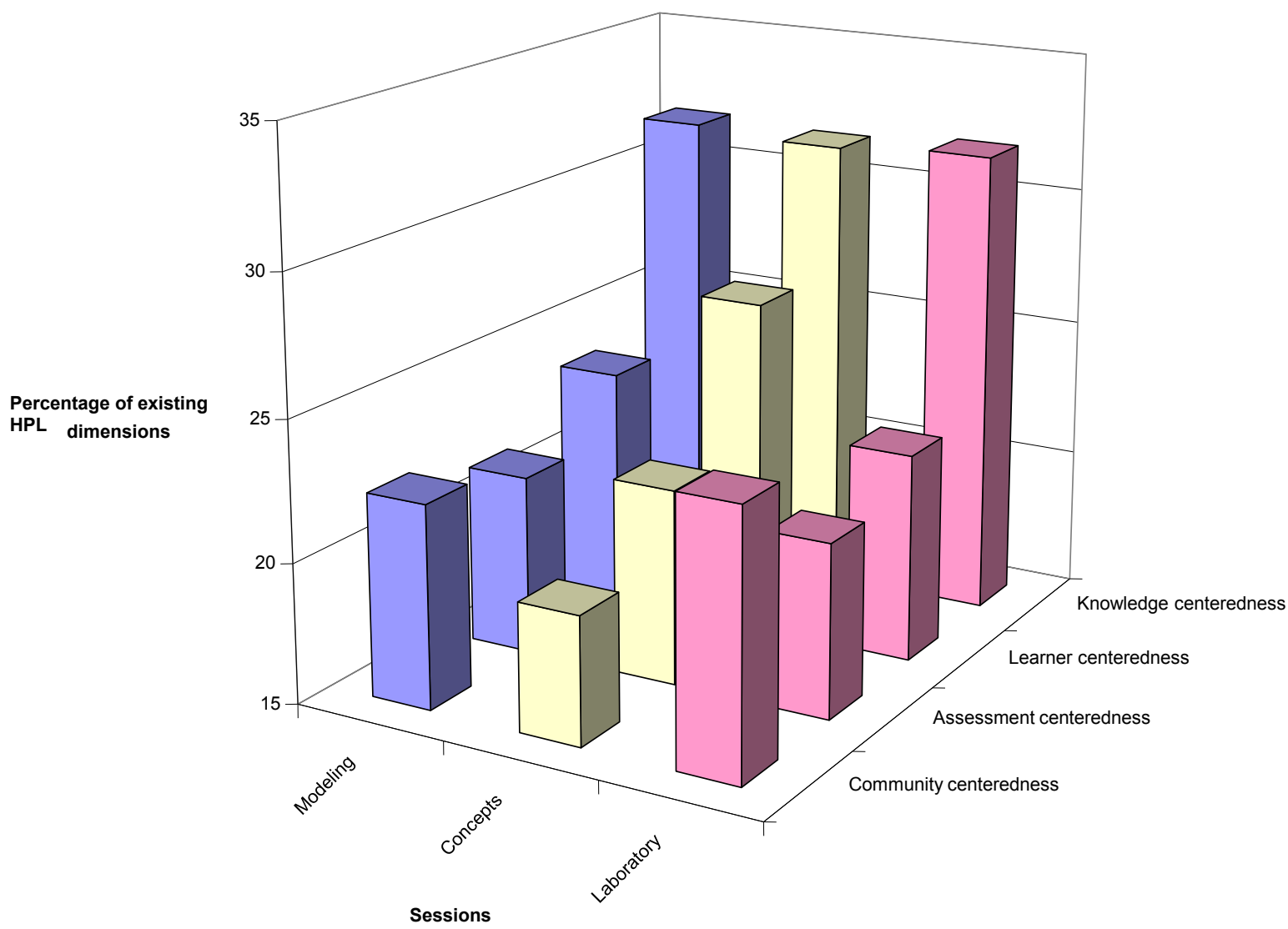

Figure 1: Percentage (average of sections 1 and 2) of existing How People Learn (HPL) dimensions (knowledge-, learner-, assessment-, and community-centeredness) in the course Introduction to Engineering Design sessions ("Modeling", "Concepts", or "Laboratory").

stakeholders while providing us with vital information to assess the redesigned course. Comprehensive results from the ethnographic study are reported elsewhere (Gazca et al., 2009b). Noteworthy, a very high percentage of the students in every semester (from 2001 to 2008) believed the course was not difficult, but the tough part was taking a course with a system so different from the one they had been accustomed to. The difficulty lies in adapting to teamwork since it is not easy to effectively communicate and work in teams. Students said that for the first time they had to be responsible, organized and persistent, and that this has also been a major change and difficult for them. Students said the course had a very heavy workload; in fact, greater than any other first-semester course. They also reported a process of adjusting, and as the semester went on they got accustomed to the structure and rhythm of the work load, they got better organized and had less trouble meeting the expectations. Nevertheless, most students believed the pace of the course was appropriate.

\subsection{Tablet PCs}

When using VOS and participatory observation, many variables came into play. In this paper we will focus on discussing the results obtained concerning the use of Tablet PCs in EI-100 three 
sessions ("Modeling", "Concepts", and "Laboratory") and two Fall 2008 sections (1 and 2). The VOS CIO instrument allowed us to determine the percentage of use of different teaching and learning media (Table 2). The overhead projectors and computers were the media most utilized in the course. Interestingly, "Concepts" and "Laboratory" sessions made greater use of computers than "Modeling". It is important to mention that CIO only covers observation of a student using the computer. Classroom and class sizes make whiteboard use difficult in EI-100, which is evident in Table 2; instead two screens and corresponding overhead projectors were heavily used. Further videos depicting real-world situations in the life of an engineer were used in all six groups (three sessions and two sections). Although Tablet PCs had been used during a previous semester, Fall 2008 was the semester they were first used as a teaching tool in EI-100 on a somewhat continuous and consistent basis. Professors had been trained in Tablet PC use, and corresponding technologies (software). Twenty Tablet PCs were available for 80 students, so use was limited to one per team of 4 students. Students also had access to one desktop computer per team; several students also used their own laptops. Tablet PCs mainly favor assessmentand community-centered learning. According to observations, the professors, especially in "Concepts" and "Laboratory" used Tablet PCs for formative in-class assessment. Professors sent students a series of questions based on an explanation of a topic or on an assigned reading. Teams received the questions on their Tablet PCs; they discussed their answers and then sent them back to the professors Tablet PC. Then, in response to students answers, the professor would provide feedback, comments or change instruction(s) accordingly. Peer evaluation was another very important Tablet PC application frequently observed in EI-100 sessions. As part of "Laboratory" coursework, students put together a design portfolio to be periodically (almost every week) assessed by the team itself, by another team and by the instructors. Rubrics that every team would download to the Tablet PC were used to self-assess (using pen-based technologies associated to the Tablet PC) their work previous to the "Laboratory". The first activity of a "Laboratory" session was to peer-assess other team work-products. After 10 minutes, the evaluating team would discuss face-to-face the rubric marks and comments with the team being evaluated. Finally, instructors would assess teams work-products using the same rubric after class.

Tablet PCs were also used to put together team presentations; the professor would ask teams to review material and prepare a presentation to explain a topic (or model, assignment, project) to their classmates. In this manner, the Tablet PC was also useful since it could be wirelessly connected to the overhead projectors. Given the large class sizes of EI-100, the professors projected the vast majority of course materials, using their Tablet PC wirelessly connected to the overhead projectors. Tablet PCs and associated technologies are excellent tools to promote community- and assessment-centered learning as can be seen in Figure 2. The graph confirms that the redesigned course is communityas well as assessment-centered (about 20 to $25 \%$ each). Percentage of Tablet PC use is also shown. Tablet PCs were utilized most in "Laboratory" sessions (30 to 34 percent), mainly favoring assessment-centered learning, but since most of the work was co-operatively performed, Tablet $\mathrm{PCs}$ are also promoting community-centered learning. "Concepts" sessions used Tablet PCs around 13 percent of the time, mainly to promote community-centered learning, but also to promote frequent formative assessments. Thanks to Classroom Presenter, instructors were able to assess students and visualize student thinking, providing opportunities for prompt feedback. "Modeling" sessions used Tablet PCs the least in activities promoting community- and assessmentcentered learning.

Tablet PCs and associated technologies generated possibilities for self-assessment, making it possible for students to anonymously analyze their own and classmates results. Another positive result of Tablet $\mathrm{PC}$ use was a visible increase in student motivation to participate in class discussions and problem-solving activities mediated through technologies (InkSurvey, WriteOn, and Classroom Presenter) associated with Tablet PCs. Figure 3 presents the relation between "problem solving activities" and "discussion activities", both desirable activities in 
Table 2: Percentage of use of selected media in the course Introduction to Engineering Design sessions ("Modeling", "Concepts", or "Laboratory") and two sections studied

\begin{tabular}{lcccccc}
\hline Type of media & \multicolumn{3}{c}{ Section 1 } & \multicolumn{3}{c}{ Section 2 } \\
\cline { 2 - 6 } & Modeling & Concepts & Laboratory & Modeling & Concepts & Laboratory \\
\hline LCD-Projector & 33.3 & 58.3 & 45.2 & 36.9 & 54.8 & 23.8 \\
Computer & 34.5 & 14.3 & 48.8 & 35.7 & 31.0 & 72.6 \\
Video & 9.5 & 2.4 & 3.6 & 8.3 & 2.4 & 2.4 \\
Demo & 3.6 & 0.0 & 0.0 & 0.0 & 0.0 & 0.0 \\
Whiteboard & 0.0 & 0.0 & 0.0 & 4.8 & 0.0 & 0.0 \\
None & 19.0 & 25.0 & 2.4 & 14.3 & 11.9 & 1.2 \\
\hline
\end{tabular}

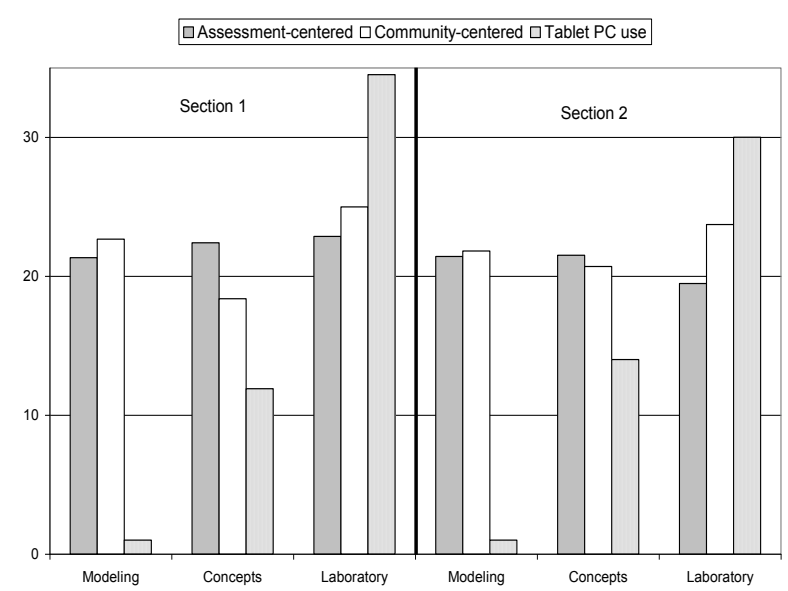

Figure 2: The percentage of Tablet PC use in relation to community- and assessmentcenteredness in the course Introduction to Engineering Design different sessions ("Modeling", "Concepts", or "Laboratory") and sections (1 or 2) studied.

students in an HPL-centered classroom. It is important to point out the differences in classroom activities among "Modeling, "Concepts", and "Laboratory" sessions. Although every session promotes problem solving (over 40 percent of all activities), "Laboratory" promotes problem solving the least and "Concepts" does so the most. Most activities in the redesigned course promoting problem solving were done using computers, and in most cases Tablet PCs, as can be observed in Figure 3 where the sphere size represents the percentage of computer use during the course.

Using the SEO instrument of VOS, students may be observed in desirable and non-desirable activities. One desirable activity is " "discussion", which is highlighted in Figure 3. "Discussion" was chosen because it is necessary in cooperative problem solving, an activity promoting knowledge-, assessment-, and communitycentered learning. The three EI-100 sessions included problem solving discussion activities (20 to 30 percent of all activities). Section 2 "Laboratory" session had the most discussion-related activities; this section also had the most computer use. A noteworthy difference exists between sections 1 and 2, and therefore between instructors. Computers were used in every session, but during "Concepts" sessions this medium was predominantly utilized as a problem-solving tool; these sessions also had a large amount of discussion-related activity in relation to problem solving. A series of informal interviews were carried out with Fall 2008 EI-100 students. The main objective of the interviews was to learn about students opinions on a series of variables, which would constitute an image of EI-100 culture (Gazca et al., 2009b). One of the variables considered was their perception of Tablet PC use. Most student comments regarding classroom Tablet PC use were favorable. The students said they had never used a Tablet PC as a learning tool and that the experience could generally be considered positive and favorable. Many students had a favorable opinion towards assessing work done by other teams. Tablet PC pen-based technologies helped a lot to do it in a "friendly" way. They said this type of activity allowed them to become aware of their own mistakes: they had not been able to identify these errors when they had self-assessed their work. Fi- 


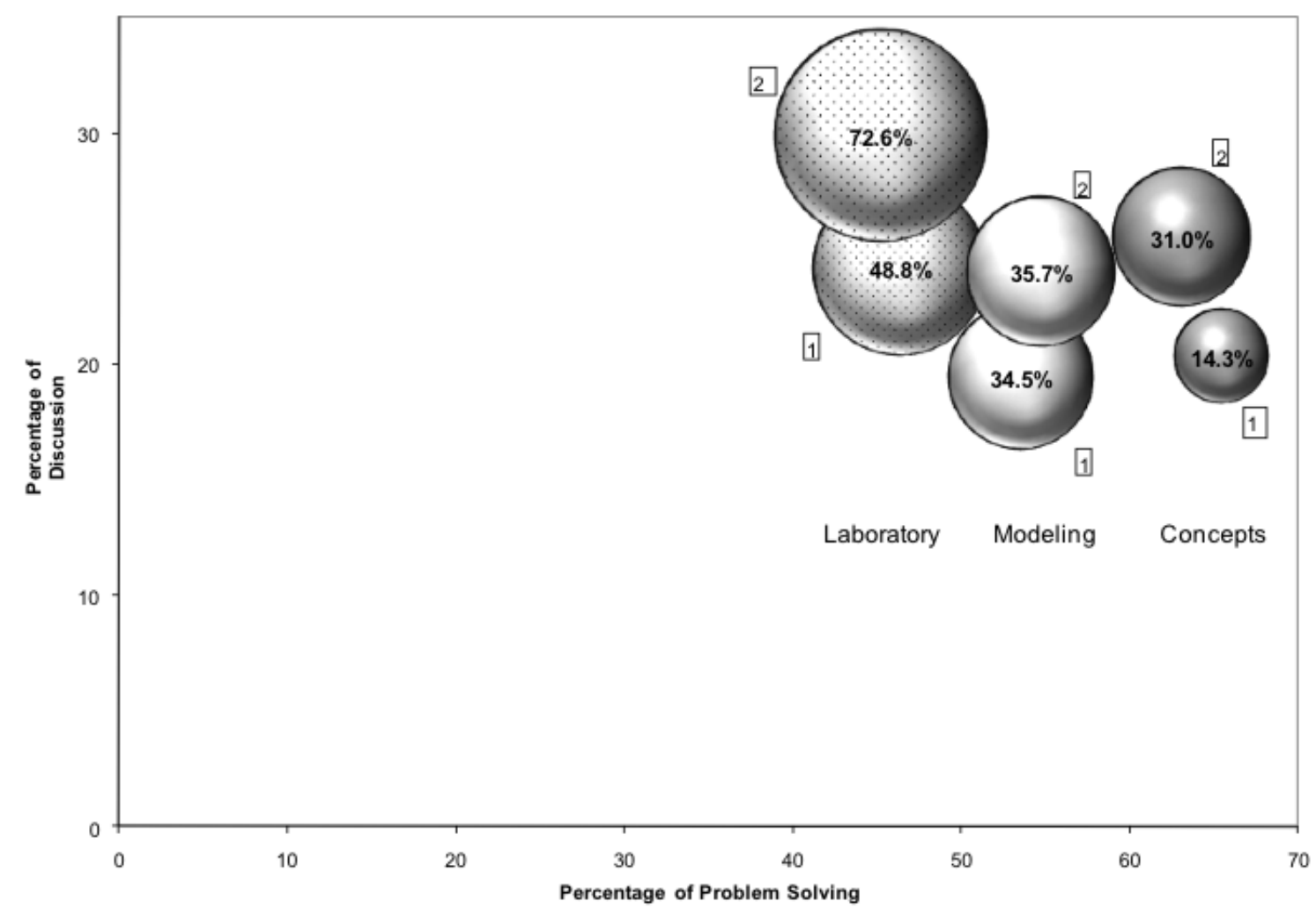

Figure 3: Percentage (sphere size) of Tablet PC use in relation to a selected HPLness relationship (problem solving vs. discussion), in the course Introduction to Engineering Design different sessions ("Modeling", "Concepts", or "Laboratory") and sections ( 1 or 2 ) studied.

nally students also said that receiving immediate feedback from their professors regarding their answers to frequent formative assessments was an excellent way to learn. Instructors said Tablet $\mathrm{PC}$ use in itself represented a radically different view of the traditional classroom, and that when combined with the HPL framework and a focus on cooperative work it could generate significant student learning, allowing not only for better learning results, but also the development of abilities such as interpersonal communication and teamwork, competencies which would otherwise be difficult to promote in the classroom. The instructors interviewed also said the Tablet $\mathrm{PC}$ is an excellent educational tool and should be used in other engineering courses, not just in the first semester. One instructor said he/she felt unskilled in the use of technologies associated with Tablet PCs and needed more training before employing them in a classroom. We believe the Tablet PC program should be extended in order to increase access to a greater number of professors and more engineering courses. Some of the disadvantages of the use of the Tablet PC for students are that they got frustrated when the Tablet PC took too long to send their answers back to the professor or when they could not receive the complete presentation or information the professor was sending (especially prior to having an ad hoc wireless network for the 
Tablet PCs). Students and professors agreed that Tablet PC use posed some problems, but the biggest one was with network connection. Some professors said one problem they encountered in classes in which computers were used (both desktop computers and Tablet PCs) was that students were more easily distracted because they could check e-mail, chat with friends, or exchange assignments from other courses.

\subsection{Outcomes}

Results presented in this paper are due to both redesign of the course taking into account the How People Learn framework and the use of Tablet PCs and associated technologies. Outcomes achieved in the redesigned course include:

1. Students improved their problem solving skills and ability to solve practical engineering problems.

2. Students had a better understanding of the Engineering Method.

3. Students improved their evaluation skills.

4. More students actively participated in class activities and discussions.

5. The classroom was more interactive and aligned with the HPL framework.

6. Feedback cycles between student teams were shortened in the "Laboratory" session of the course.

7. Instructors provided immediate feedback to students, corrected misunderstandings, and refined instruction to meet students needs.

8. Instructors understood how to use technology to transform instruction and enriched the learning environment.

9. Instructors created a community of practice and worked collaboratively to continually improve the course.

\section{Conclusion}

The redesign of the first semester undergraduate course Introduction to Engineering Design using Tablet PCs and guidelines from research on How People Learn increased active student participation. Formative assessment and feedback were more common and rapid. Teachers (instructors) utilized the information gained through real-time formative assessment by means of Tablet PC technologies to tailor instruction to meet student needs. In the "Laboratory" session of the course peer-team formative assessments and feedback processes were improved while decreasing work-products resubmission. The redesigned course also improved student understanding of the engineering method, including problem solving heuristics and modeling, and students abilities to solve practical engineering problems and complete real world engineering projects. The VaNTH Observation System captured important differences in classroom experiences. These differences may be used to measure levels of "HPLness" of a lesson. Moreover the VaNTH Observation System clearly captured differences among instructors teaching styles and identified the effects of the three different course sessions ("Modeling", "Concepts", and "Laboratory"). In addition, it generated detailed feedback that instructors may use to self-assess and further refine course redesign.

\section{Acknowledgements}

We acknowledge financial support from HEWLETT-PACKARD (HP), through the HP Technology for Teaching Higher Education Grant Initiative for Latin America for the project "High-Quality Learning Environments for Engineering Design: Using Tablet PCs and Guidelines from Research on How People Learn". Author Gazca acknowledges financial support for her $\mathrm{PhD}$ studies from the National Council for Science and Technology of Mexico (CONACyT) and Universidad de las Américas Puebla. We appreciate the hard work and thoughtful critiques of EI-100 students and teaching assistants.

\section{References}

Anderson, R., McDowell, L., \& Simon, B. (2005). Use of Classroom Presenter in engineer- 
ing courses. In Proceedings of the 35th ASEE/IEEE Frontiers in Education Conference. doi:10.1109/FIE.2005.1611913

Angelo, T. A., \& Cross, K. P. (1993). Classroom assessment techniques: a handbook for college teachers. Jossey-Bass.

Birol, G., Liu, S. Q., Smith, H. D., \& Hirsch, P. (2006). Educational modules in tissue engineering based on the "how people learn" framework. Bioscience Education Electronic Journal, 7(May), 6. Retrieved from http: / / www . bioscience . heacademy . ac . uk / journal / vol7 / beej - 7 6.aspx

Bransford, J., Vye, N., \& Bateman, H. (2002). Creating high-quality learning environments:guidelines from research on How People Learn. In I. Stacey \& P. A. Gram (Eds.), The knowledge economy and postsecondary education report of a workshop (pp. 159-198). National Academies Press. Retrieved from http:// www . nap.edu / openbook . php ? record_id $=10239 \&$ page $=$ 159

Bransford, J. D., \& Schwartz, D. L. (1999). Rethinking transfer: a simple proposal with multiple implications. Review of Research in Education, 24(1999), 61-100. Retrieved from http://www.jstor.org/pss/1167267

Bransford, J. D., Brown, A. L., \& Cocking, R. R. (2000). How People Learn: brain, mind, experience, and school: expanded edition. National Academies Press. Retrieved from http : / / www . nap . edu / catalog . php ? record_id $=9853$

Cordray, D. S., Harris, A. H., \& Harris, T. R. (2007). A closer look at the VaNTH/ERC biomedical engineering modules: a method to examine the effects of selected core components of the "legacy cycle" and HPL model, In Proceedings of the annual ASEE Conference. Retrieved from http:// search . asee.org / search $/$ fetch ; jsessionid $=$ bd2mn8ls $3 \mathrm{w} 2 \mathrm{n}$ ? url $=$ file $\% 3 \mathrm{~A} \quad \% \quad 2 \mathrm{~F} \quad \%$ 2Flocalhost $\%$ 2FE \% 3A \% 2Fsearch \% 2Fconference \% 2F14 \% 2FAC \% 25202007Full1793 . pdf \& index $=$ conference_papers \& space $=$ 129746797203605791716676178 \& type = application $\% 2$ F pdf\&charset=
Cox, M. F., \& Cordray, D. S. (2008). Assessing pedagogy in bioengineering classrooms: quantifying elements of the "How People Learn" model using the VaNTH observation system (vos). Journal of Engineering Education, 97(4), 413-431. Retrieved from http: / / docs.lib. purdue.edu / cgi / viewcontent . cgi $?$ article $=1000 \&$ context $=$ enepubs

Cox, M. F., \& Harris, A. H. (2006). VaNTH observation system component assessment, In Proceedings of the ASEE Annual Conference. Retrieved from http : / / search . asee . org / search / fetch ? url $=$ file $\% 3 \mathrm{~A} \%$ 2F $\%$ 2Flocalhost $\%$ $2 \mathrm{FE} \% 3 \mathrm{~A} \%$ 2Fsearch $\%$ 2Fconference $\%$ 2F19 \% 2FAC \% 25202009Full1071 . pdf \& index $=$ conference_papers \& space $=$ 129746797203605791716676178 \& type $=$ application $\% 2$ Fpdf\&charset $=$

Dym, C. L., Agogino, A. M., Eris, O., Frey, D. D., \& Leifer, L. J. (2005). Engineering design thinking, teaching, and learning. IEEE Engineering Management Review, 34(1), 6565. Retrieved from http:// citeseerx.ist. psu.edu/viewdoc/download? doi=10.1.1. $72.1593 \&$ rep $=$ rep $1 \&$ type $=$ pdf

Felder, R. M., Woods, D. R., Stice, J. E., \& Rugarcia, A. (2000). The Future of Engineering Education II. teaching Methods that Work. Chemical Engineering Education, 34(1), 26-39.

Gazca, L., Palou, E., López-Malo, A., \& Garibay, J. M. (2009a). Capturing differences of engineering design learning environments by means of VaNTH observation system., In Proceedings of the 39th ASEE/IEEE Frontiers in Education Conference. Retrieved from http:// search . asee .org / search / fetch ? url = file \% 3A \% 2F \% 2Flocalhost \% 2FE \% 3A \% 2Fsearch \% 2Fconference \% 2F12\% 2F2006Full1790. pdf \& index $=$ conference_papers \& space $=$ 129746797203605791716676178 \& type $=$ application $\% 2$ Fpdf\&charset $=$

Gazca, L., Palou, E., López-Malo, A., \& Garibay, J. M. (2009b). Ethnography of a first-year design experience in the introduction to engineering design course., In Proceedings of the 39th ASEE/IEEE Frontiers in Ed- 
ucation Conference. Retrieved from http: / / fie2012.org/sites / fie2012.org / history / fie2009/papers/1537.pdf

Harris, A. H. (2003). A manual for the VaNTH observation system. VaNTH Engineering Research Center.

Harris, A. H., \& Cox, M. F. (2003). Developing an observation system to capture instructional differences in engineering classrooms. Journal of Engineering Education, 92(4), 329-336.

Jenkins, J. J. (1979). Four points to remember. a tetrahedral model of memory experiments. In L. S. Cermack \& F. I. M. Craik (Eds.), Levels of processing in human memory (pp. 429-446). Erlbaum.

Johnson, D. W., Johnson, R. T., \& Smith, K. (1998). Active learning: cooperation in the college classroom. Interaction Book Co. Retrieved from http://unbc.pbworks.com/f/ Active+Learning.PDF

Kowalski, F., Kowalski, S., \& Hoover, E. (2007). Ac 2007-2519 : using InkSurvey: a free web-based tool for open-ended questioning to promote active learning and real-time formative assessment of tablet pc-equipped engineering students., In Proceedings of the 2007 ASEE $\mathrm{Na}$ tional Conference Exposition. Retrieved from http : / / search . asee . org / search / fetch $?$ url $=$ file $\% 3 \mathrm{~A} \% 2 \mathrm{~F} \%$ 2Flocalhost $\%$ $2 \mathrm{FE} \% 3 \mathrm{~A} \% 2 \mathrm{Fsearch} \% 2 \mathrm{~F}$ conference $\%$ 2F14 \% 2FAC \% 25202007Full2519 . pdf \& index $=$ conference_papers \& space $=$ $129746797203605791716676178 \&$ type $=$ application\%2Fpdf\&charset=

LeCompte, M. D., \& Schensul, J. J. (1999). Designing and conducting ethnographic research. AltaMira Press.

Palou, E., \& Tamborero, J. F. (2009). Introducción al Diseño en Ingeniería. In Memorias de la XXIX Conferencia Nacional de Ingeniería.

Pellegrino, J. W., Chudowsky, N., \& Glaser, R. (2001). Knowing what students know: the science and design of educational assessment. National Academies Press. Retrieved from http://www.nap.edu/catalog.php? record_id=10019
Schwartz, D. L., \& Bransford, J. D. (1998). A time for telling. Cognition and Instruction, 16(4), 475-522. Retrieved from http:// www.jstor.org/stable/3233709

Shavelson, R. J., \& Towne, L. (2002). Scientific research in education. National Academies Press. Retrieved from http://www. nap. edu/catalog/10236.html

Tront, J. G., Eligeti, V., \& Prey, J. (2006). Classroom presentations using tablet PCs and WriteOn. In Proceedings of the 36th ASEE/IEEE Frontiers in Education Conference. San Diego, CA. Retrieved from http://fie-conference.org/fie2006/papers/ 1270.pdf

Wiggins, G. P., \& McTighe, J. (1997). Understanding by design (Expanded 2nd edition.) (U. Box, Ed.). Association for Supervision and Curriculum Development. Prentice Hall.

Wise, J. C., Toto, R., \& Yon Lim, K. (2006). Introducing tablet pcs: initial results from the classroom. In Washington DC: American Society for Engineering Education (Ed.), Proceedings of the 36th ASEE/IEEE Frontiers in Education Conference. 36th ASEE/IEEE Frontiers in Education Conference. Retrieved from http : / / fie conference.org/fie2006/papers/1683.pdf 